\title{
The role of major virulence factors and pathogenicity of adherent-invasive Escherichia coli in patients with Crohn's disease
}

\author{
Khalid A. Abdelhalim¹ ${ }^{1}$ Ataç Uzel ${ }^{1}$, Nalan Gülşen Ünal ${ }^{2}$ \\ ${ }^{1}$ Basic and Industrial Microbiology Section, Department of Biology, Faculty of Science, Ege University, Izmir, Turkey \\ ${ }^{2}$ Department of Gastroenterology, Faculty of Medicine, Ege University, Izmir, Turkey \\ Gastroenterology Rev 2020; 15 (4): 279-288 \\ DOI: https://doi.org/10.5114/pg.2020.93235
}

Key words: adherent-invasive Escherichia coli, Escherichia coli, Crohn's disease, inflammatory bowel disease, virulence factors.

Address for correspondence: Khalid A. Abdelhalim, Basic and Industrial Microbiology Section, Department of Biology, Faculty of Science, Ege University, Izmir, Turkey, e-mail: khaled.abdallah89@yahoo.com

\begin{abstract}
Inflammatory bowel disease (IBD) is a term that describes Crohn's disease (CD) and ulcerative colitis (UC), and these two conditions are characterised by chronic inflammation of the gastrointestinal tract. Dysbiosis of intestinal microbiota has been consistently linked to patients with IBD. In the last two decades, the progressive implication of adherent-invasive Escherichia coli (AIEC) pathogenesis in patients with CD has been increasing. Here we discuss recent findings that indicate the role and mechanisms of AIEC in IBD. We also highlight AIEC virulence factor genes and mechanisms that suggest an important role in the severity of inflammation in CD patients. Finally, we emphasise data on the prevalence of AIEC in CD patients.
\end{abstract}

\section{Introduction}

In the last decade, many microorganisms have been progressively linked in the pathogenesis of inflammatory bowel disease (IBD) - mainly Crohn's disease (CD). Escherichia coli and particularly the adherent invasive E. coli (AIEC) pathotype, has been increasingly implicated in the etiopathogenesis of $C D$, but until today the mechanism of AIEC in the pathogenesis of $C D$ remains uncharted. Significant progress has been made in recent studies on explaining the pathogenicity mechanisms of AIEC in CD patients. At the molecular level, however, the characteristics of this strain remain controversial.

The human gut microbiota composes a population of approximately $10^{14}$ commensal microorganisms. Their genomes (also called metagenome or microbiome) are about 150 times the size of the human genome in terms of the number of genes [1]. In fact, the microbiota has an effect on the physiology and metabolism within the body. Moreover, to affecting the metabolism of the host, microbiota could also be involved in several pathological mechanisms. Activation and the development of the mucosal immune system in the gastroin- testinal (GI) tract depend on the complex association of these microorganisms [2]. Recent studies have linked to the role of the human gut microbiota in several human diseases, such as colon cancer, IBD, type 1 diabetes, insulin resistance, non-alcoholic fatty-liver disease, allergies, and asthma [3]. Therefore, it is very important to understand the connection of the microbiota in the aetiology of such diseases by distinguishing species that compose a healthy microbiota [4-9].

The influence of the microbiota on human health is best demonstrated by studies in IBD, such as CD and ulcerative colitis (UC) [10-12]. Both CD and UC represent serious medical disorders noticeable by abnormal inflammation within the human Gl tract, which results in serious clinical outcomes in affected patients. These diseases are very complex and involve the contribution of genetic factors as well as external factors such as geographical area [13]. IBD is caused by a dysfunction of the human immune response to gut microbiota and occurs in the case of host genetic susceptibility. CD is a chronic and commonly incapacitating inflammatory intestinal disorder, whose prevalence and incidence are on the rise in developed countries [14]. 
The aim of this review is to discuss recent findings that indicate the role and mechanisms of AIEC in IBD, and to highlight the AIEC virulence factor genes and their mechanisms that suggest playing a crucial role in the severity of inflammation in CD patients. It is also aimed to discuss the current data on the prevalence of AIEC in CD patients.

\section{The role of Escherichia coli in inflammatory bowel disease}

Escherichia coli strains have been classified into seven (A, B1, B2, C, D, E, and F) phylogenetic groups according to virulence factors. Recently, the pathogenesis of IBD has been linked to human intestinal microbiota [15] Patients with CD display an altered gut microbial community, and the imbalance (dysbiosis) present in patients with colonic and ileac CD is different [16]. In contrast, a specific gut microbiota imbalance is beginning to be identified in UC patients, but differences between studies have inhibited attempts to reach a clear conclusion to date [16-19]. E. coli is the most prominent bacterium in CD aetiology in the last $10-15$ years $[20,21]$ (Table I) [22-30]. The growth of the E. coli population in IBD patients is currently unexplained, but that may be due to the association with increased production of reactive nitrogen species, allowing nitrate respiration, which confers $E$. coli a fitness advantage [31]. Recent studies based on cultural and molecular techniques support the theory that $E$. coli is an important microbial factor involved in CD pathogenesis, but some disagreement exists regarding its role in UC pathogenesis [17-19, 32-34]. In this section, we examine the recently published data on E. coli populations in CD patients related to their abundance, consortium associated with disease activity, and alteration of the human gut muco- sa. We have also focused on the pathogenic properties of the strains to highlight evidence supporting or limiting the inclusion of this bacterium into the IBD subtype.

Recently, an elevated number of mucous AIEC strains have been isolated from the gut mucosa of $C D$ patients [35-38]. This has led to the illustration and identification of a new bacterial strain known as AIEC, which is characterised by its particular capacity to adhere and invade the cells of human small intestines, especially ileal cells [33, 39].

\section{The most common virulence factors in adherent-invasive Escherichia coli strains}

As mentioned previously, AIEC strains were extensively linked to many aspects of CD pathogenesis, and their virulence factors were compared in the reference AIEC LF82 strain and non-AIEC strains. Despite all the research on AIEC pathogenicity, the exact genetic factors that could define it as a feature of the AIEC prototype are still unknown. The majority of genes studied for AIEC pathogenicity are not AIEC-specific genes as for the fim $H, h t r A, d s b A$ or ompA genes, and these genes are also found in most $E$. coli strains, including non-pathogenic $E$ coli [40-43].

E. coli possess fimbriae as a virulence factor, which confers pathogenic strains with the ability to adhere to and colonise various specific host epithelia. So far, the fimH gene is one of the most studied virulence factors in AIEC strains. The FimH gene encodes an adhesion characteristic that allows the bacterial adhesion to glycosylated and non-glycosylated host receptors, as well as the matrix-associated type I and IV collagens, glycosylated receptors, fibronectin, and laminin [44]. Even though almost all E. coli strains comprise type 1 pili including

Table I. Abnormal prevalence of E. coli in Crohn's disease patients in the last 5 years

\begin{tabular}{|c|c|c|c|c|}
\hline Date & Country & Method & Sample & Reference \\
\hline 2013 & United States of America & Culture & Ileal biopsies & 22 \\
\hline 2013 & China & qPCR & Faeces & 23 \\
\hline 2013 & United Kingdom & Culture & Ileal, ileocolonic, and colonic biopsies & 24 \\
\hline 2014 & Spain & $\mathrm{qPCR}$ & Ileal, ileocolonic, and colonic biopsies & 25 \\
\hline 2014 & Australia & $\mathrm{qPCR}$ & Ileal, ileocolonic biopsies & 26 \\
\hline 2014 & Italy & PFGE\& RAPD & Ileal biopsies & 27 \\
\hline 2015 & India & RT-qPCR & Colonic biopsies & 28 \\
\hline 2017 & Australia & Culture \& ELISA & Terminal ileal biopsies & 29 \\
\hline 2017 & Spain \& Chile & qPCR \& culture & Chilean (ileal biopsies), Spanish (colon or Ileal biopsies) & 30 \\
\hline
\end{tabular}

$g P C R$ - Quantitative polymerase chain reaction, RT-QPCR-reverse transcription quantitative polymerase chain reaction, PFGE-pulsed-field gel electrophoresis, RAPD - random amplification of polymorphic DNA, ELISA - enzyme-linked immunosorbent assay. 


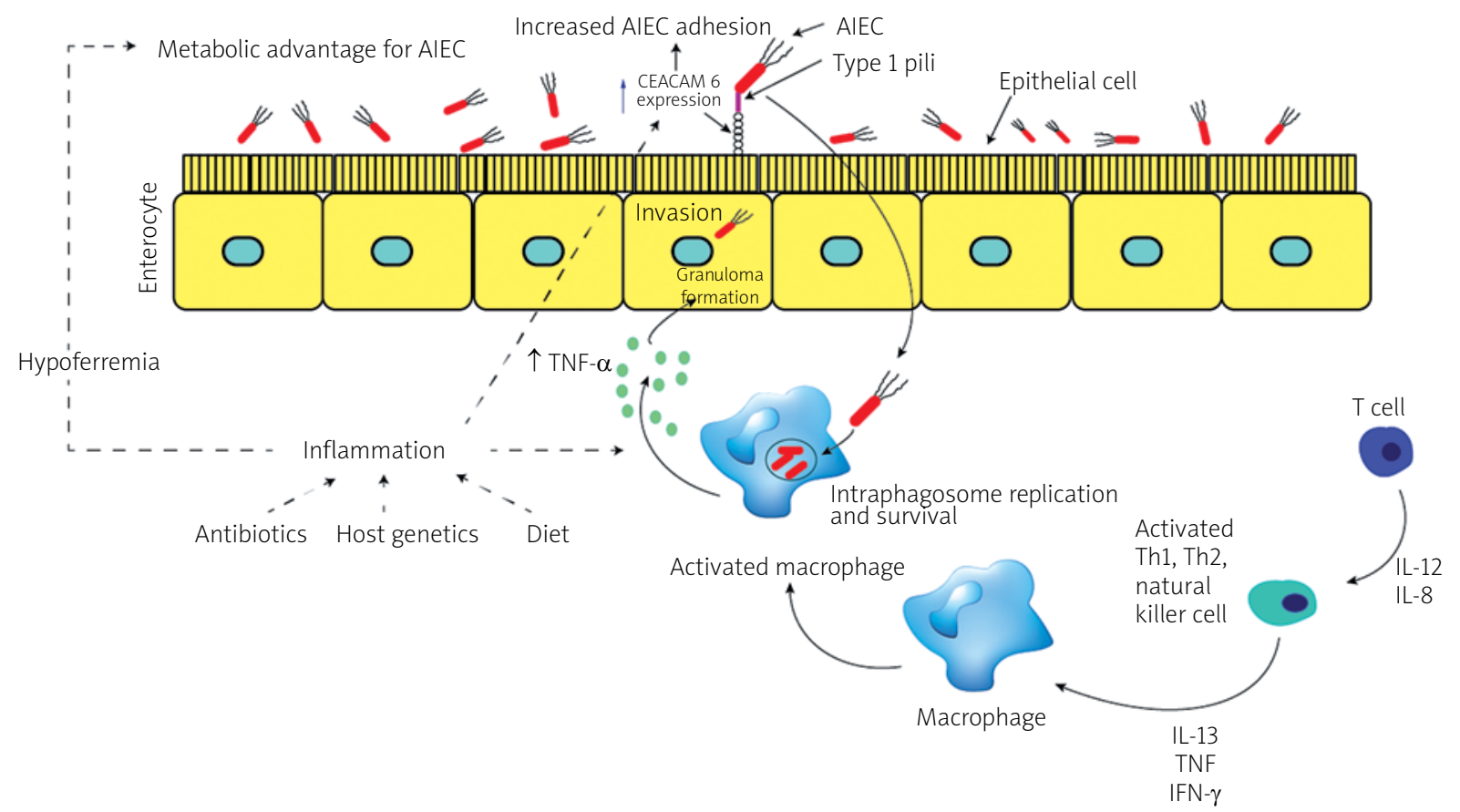

Figure 1. The diagram shows changes in the gut during inflammation mediated by adherent-invasive Escherichia coli (AIEC) colonisation. Inflammation of the human gut can be triggered by several factors including diet, antibiotic administration, acute gastroenteritis, and host genetics. The pro-inflammation in human gut mediates noticeable changes in the gut, which can appear as hypoferremia and over-expression of carcinoembryonic antigen-related cell adhesion molecule (CEACAM6) surface receptors produced by epithelial cells in human gut. AIEC strains have been evolved and gained a competitive advantage in inflamed gut of the human intestines. This evolution includes the ability of AIEC strains to use a modified fimH protein to bind to CEACAM6 and to be able to utilise amine $(\mathrm{N})$ and sulphur (S) oxides as electron acceptors

AIEC - adherent-invasive Escherichia coli, CEACAM6 - carcinoembryonic antigen-related cell adhesion molecule, Th - Thelper, IL - interleukin, TNF- $\alpha$-tumour necrosis factor $\alpha$, IFN- $\gamma$ - interferon $\gamma$.

non-pathogenic strains, most AIEC strains generally offer a variation of $\mathrm{fimH}$ adhesion, which makes them more effective for binding to human intestinal epithelial cells [40]. Some other non-AIEC strains possess these mutations as well, but these strains do not exhibit type 1 pili. Mutation of the fimH gene in AIEC strains can increase the ability to adhere to expressed carcinoembryonic antigen-related cell adhesion molecules (CEACAM6) in intestinal epithelial cells (Figure 1). The expression of type 1 pili and long polar fimbriae (LPF) of AIEC strains allows target $M$ cells on Peyer's patches, which help to translocate across the barrier of intestinal epithelial cells [3]. LPF is considered a pathogenic feature and is one of the characteristics of AIEC strains in CD (Table II) [45-61].

Nevertheless, recent studies have shown that the fimH gene does not show any significant association with AIEC pathotype; this gene has been detected in both AIEC and non-AIEC strains [30]. However, a higher rate of the fimH gene has been reported in AIEC strains isolated from biopsy samples of patients with UC com- pared to control subjects [62]. The FimH gene is the only gene that has been detected in all AIEC strains, mainly in B2 phylogenetic group E. coli [29]. The fimH gene and its protein were found to play an important role in the binding of $E$. coli to human epithelial colorectal adenocarcinoma (Caco-2) cells. A higher similarity between fim $H$ alignments in the B2 phylogroup and adhesive strain of E. coli has been detected [63].

Invasion of the brain endothelium protein A (ibeA) gene; some extra-intestinal pathogenic E. coli (ExPEC) strains from phylogenetic group (B2) and especially new-born meningitis and avian pathogenic strains carry this virulence gene. The ibeA gene has invasion characteristics that allow $E$. coli $\mathrm{K} 1$ to invade blood brain barrier. The ibeA gene was originally characterised and cloned from the chromosome of an invasive E. coli K1, which has been isolated from cerebrospinal fluid [64]. E. coli $\mathrm{K} 1$ carrying the ibeA gene is thought to contribute to the pathology of neonatal meningitis E. coli (NMEC) and is responsible for most cases of meningitis in ne- 
Table II. Virulence factors described in AIEC strains

\begin{tabular}{|c|c|c|}
\hline Gene name & Gene description & Reference \\
\hline \multicolumn{3}{|l|}{$\begin{array}{l}\text { Genes involved in } \\
\text { adhesion and invasion } \\
\text { of intestinal epithelial } \\
\text { cells: }\end{array}$} \\
\hline FimH Type 1 & Type 1 fimbrial adhesin & $46-48$ \\
\hline K 1, kpsMTII & Capsule synthesis & 49 \\
\hline$a f a c$ & Afimbrial adhesin & 50 \\
\hline ompC & Outer membrane protein & 51 \\
\hline ipaH & Invasive plasmid antigen & 52 \\
\hline ial & Invasion-association locus & 52 \\
\hline chiA & Chitinase & 3 \\
\hline \multicolumn{3}{|l|}{$\begin{array}{l}\text { Metabolic regulation } \\
\text { and toxins: }\end{array}$} \\
\hline chuA & Heme transport system & 53 \\
\hline irp2 & Iron-regulatory proteins & 30,53 \\
\hline sit operon/sitA & $\begin{array}{l}\text { Iron and manganese } \\
\text { uptake system/permease }\end{array}$ & 53,54 \\
\hline pdu operon/pduc & $\begin{array}{l}\text { Propanediol utilisation/ } \\
\text { large subunit of } \\
\text { propanediol dehydratase }\end{array}$ & $53,29,55$ \\
\hline fyuAlybt & $\begin{array}{l}\text { Yersiniabactin siderophore } \\
\text { system }\end{array}$ & 53,54 \\
\hline flhDC and fliA & Flagellar regulators & 56,57 \\
\hline ratA & $\begin{array}{c}\text { Ribosome association } \\
\text { toxin }\end{array}$ & 30,58 \\
\hline$h f q$ & RNA-binding protein & 59 \\
\hline \multicolumn{3}{|l|}{$\begin{array}{l}\text { Peyer's patches } \\
\text { interaction and } \\
\text { survival inside } \\
\text { macrophages: }\end{array}$} \\
\hline$i b e A$ & $\begin{array}{l}\text { Invasion of brain } \\
\text { endothelium protein A }\end{array}$ & 49 \\
\hline Ipfoperon & Long polar fimbriae & 45 \\
\hline htrA & $\begin{array}{l}\text { High-temperature } \\
\text { requirement A stress } \\
\text { protein }\end{array}$ & 60 \\
\hline$d s b A$ & Periplasmic oxidoreductase & 61 \\
\hline
\end{tabular}

onates $[64,65]$. NMEC strains harbour the ibeA gene, which is associated with reductive evolution, indicating a high degree of protection [66]. This gene is responsible for the interaction of AIEC strains with human intestinal epithelial cells and macrophages, as well as colonisation of the mouse intestines.

Several studies have been conducted to identify virulence factors associated with the AIEC phenotype. The
ibeA virulence gene, which plays a role in invasion, was more common in the $E$. coli isolates in $C D$ patients than in controls [67]. However, ibeA gene has been also detected in the genome of AIEC strain (NRG857c), and this gene contributes to the invasion, macrophage survival, and inflammatory response in the murine intestine [68].

Regarding to the molecular mechanisms mediating ibeA gene interactions with host cells, existing data are quite insufficient. However, this gene was reported as a 50-kDa outer membrane protein containing seven predicted trans-membrane domains with expanded layers passing from the cell membrane to the extracellular space [68]. According to recent reports, the ibeA gene can bind host proteins as potential receptors, including polypyrimidine tract-binding protein (PTB)-associated splicing factor (PSF), a RNA-binding component of spliceosomes, and vimentin (a type III intermediate filament (IF) protein that is expressed in mesenchymal cells) $[27,69]$.

The ibeA gene encodes an RNA polymerase and sigma $S$ (RpoS)-like regulator with a narrow functional spectrum, which is considered to play a part in bacterial virulence adaptation in some NMEC strains, and this gene also located in the same operon with other genes (ibeR and ibeT) [70]. It is not known whether ibe $A$ is regulated by ibe $R$, but brain endothelial cell invasion is affected by the absence of ibeA [70]. However, the ibeT gene is located near to ibeA and has been linked to affect invasion and adhesion of brain endothelial cells, even though it shows sequence homology to $\mathrm{Na}^{+} / \mathrm{H}^{+}$ antiporters [71].

Polysaccharide K capsule gene - many pathogenic E. coli strains, including AIEC strains, carry a polysaccharide $\mathrm{K}$ capsule that protects the bacterium against host innate immune factors, and it plays a major role in resistance and survival during infection. The pathogenic ExPEC strains express a polysaccharide capsule that is important both pathogenically and taxonomically $[72,73]$. Commensal E. coli carries a high-molecular-weight, low-charge-density group 1 capsule; in contrast, EXPEC carries low-molecular-weight, high-charge-density group 2 and 3 capsules that protect ExPECs against phagocytosis and complement-mediated killing, thereby contributing to extra-intestinal virulence [72, 74-78]. Nevertheless, the characterisation of this $\mathrm{K}$ antigen is highly specialised and cannot be performed in any laboratory. In contrast, molecular detection of kps antigens can be performed in any molecular laboratory. Kps 2 and 3 operons share moderate and highly conserved regions that encode transport and assembly functions, which combine with type-specific regions that encode the synthesis of the specific component sugars of the particular polysaccharide [79-84]. The contribution of 
capsular antigen is well established in uropathogenic E. coli (UPEC) and protects against phagocytosis and complement-mediated killing [85, 86].

In laboratory animals such as mice, $\mathrm{K} 1$ contributes to the development of intracellular bacterial communities that are biofilm-like bacterial aggregates in superficial bladder epithelial cells during the early stages of acute urinary tract infections (UTI) [87]. K1 serotype is highly associated with bacterial strains that cause blood infection, meningitis, and UTI [86, 87]. K1 capsule is made from sialic acid chain residues that are synthesised by enzymes encoded by genes in region II of the capsule locus (neuDBACES), and this polysaccharide is similar to the polysialic acid found on some human cells, and due to molecular mimicry the $\mathrm{K} 1$ antigen is considered poorly immunogenic [88].

$K 1, K 5$, and $k p s M T / /$ genes are involved in the synthesis of capsular materials and are important in the virulence of bacteria. These genes have recently been identified in the AIEC LF82 strain [89-92]. A positive association between capsular genes ( $K 1$ and kpsMT II) in paediatric patients with $C D$ has also been detected [67]. The importance of these genes and their presence only in CD patients could additionally support that AIEC strains may persist in CD.

Virulence gene ferric hydroxamate uptake protein $D$ $(f h u D)$, outer membrane hemin receptor (chuA), and iron-regulatory proteins (irp2) are suggested to be related with iron uptake. Iron is an essential element for all microorganisms, except some Lactobacilli. In fact, total iron in the human body amounts to about 4-5 $\mathrm{g}$ and it is not readily available for the bacteria because the iron is bound to eukaryotic proteins such as ferritin, transferring, haemoglobin, and lactoferrin. A host with a poor iron environment is a clear sign that influences the mechanism of iron acquisition. A low-molecular-weight $\mathrm{Fe}^{3+}$ binding compound (siderophores) will be synthesised by the bacteria to transport and solubilise the iron to the bacteria, and $\mathrm{Fe}^{3+}$-siderophore complex is brought into the cell by a membrane protein [93]. Pathogenic bacteria have developed different mechanisms to obtain and compete with the host for iron, which is an essential growth factor for the host and the bacteria [94]. However, a lack of iron generates the expression of some virulence factors such as toxins [95-97] and haemolysins [98-100].

The fhuD gene; $E$. coli possesses a ferric hydroxamate transport system, which is a soluble periplasmic binding protein. $\mathrm{Fe}^{3+}$ cannot be transported a mono-atomic ion because of its extreme insolubility. Iron is bound to low-molecular-weight carriers designated siderophores in microbes. E. coli $\mathrm{Fe}^{3+}$ siderophores have to be translocated across two membranes for uptake into the cells. After conversion of E. coli cells to spheroplasts fhuD protein is released, which indicates a location in the periplasmic space between the outer membrane and the cytoplasmic membrane [101]. The properties of this protein are typical for bacterial periplasmic binding protein-dependent transport systems (PBPs) through which peptides, amino acids, anions, vitamins, and some sugars are absorbed [101].

The chuA gene is a haeme iron acquisition gene. Several pathogenic $E$. coli strains carry this gene as an outer membrane protein responsible for haemin utilisation. A Recent study identified the chuA gene, which encodes the 69-kDa outer membrane protein responsible for haeme uptake in E. coli 0157:H7 [102]. This gene is part of the haeme transport locus, which is widely distributed among pathogenic E. coli strains [103]. Iron is an essential element for growth of AIEC, and the AIEC strains that are enriched with siderophores (chu operon) are able to survive and persist inside $\mathbf{7 7 4}$ macrophages, which can be suggested as a major contributor to acquiring and using iron and could encourage the multiplication of AIEC in inflamed human intestines [53]. Within macrophages, AIEC could selectively utilise the host defects in autophagy [104], by upregulating of the chuA gene and stimulating the release of TNF- $\alpha$ to promote and enhance dysbiosis, multiplication, and persistence of AIEC $[105,106]$.

The irp2 gene regulates the post-transcriptional expression of mRNAs that encode certain proteins involved in iron utilisation and homeostasis [107-109]. Disorders of iron metabolism can cause major health problems because iron is a very important element for cellular functions. It can be linked to some metabolic processes, such as cell growth, inflammation, and apoptosis. Vertebrate iron metabolism and transcriptionally regulated expression of the major iron homeostasis genes are controlled by iron-regulatory proteins-2 (IRP2) [110]. Recent studies have shown that virulence genes related to iron uptake ( $f u D, c h u A$, and irp2) have been detected in AIEC strains in patients with CD [30,53]. Pathogenic and non-pathogenic $E$. coli strains carry the fhuD gene; however, the chuA and irp 2 genes are less common among diarrhoeagenic and commensal E. coli strains [30]. Nonetheless, ExPEC strains carry both these genes. The presence of fhuD, chuA, and irp 2 genes or the presence of just the chuA gene alone may play a crucial role in detecting AIEC in patients with CD [30]. This can be a suitable biological and diagnostic marker that can be used to identify and characterise AIEC strains in $C D$ patients.

Ferric yersiniabactin uptake receptor (fyuA) gene acts as a receptor for iron yersiniabactin (Fe-Ybt) siderophore uptake [111-113]. The virulence in many mem- 
bers of the Enterobacteriaceae family has been linked to this gene $[113,114]$. This gene not only acts as a siderophore uptake receptor but is also involved in biofilm formation. Nevertheless, the role of the fyuA gene in biofilm formation is not known yet, nor whether the effect is due to a decrease in concentration of intracellular iron or as a result of another mechanism that remains to be explained [115]. The fyuA gene has been identified in AIEC-like strains isolated from CD patients [67]. Pathogenic bacteria grow and multiply by using $\mathrm{Hb}$ or haem as the sole iron source. These pathogenic bacteria obtain an entrance to the intracellular haeme reservoir alongside starting tissue invasion by secreting certain cytotoxins. During the progression of infection in CD patients, cytotoxin production combined with the haeme or/and haemoglobin using capacity to could assist the effect of iron acquisition.

The high-pathogenicity island ( $\mathrm{HPI}$ ) present in pathogenic Yersinia, which carries genes like fyuA that are involved in the transport, regulation, and synthesis of the siderophore yersiniabactin, has been detected in various strains of $E$. coli [116]. However, HPI has been detected in verotoxin-producing $E$. coli and does not appear to contribute to pathogenicity, but it can contribute to the strain fitness of E. coli [117]. Furthermore, E. coli strains carrying HPI have been linked to diarrhoea in humans [118].

Ribosome-association toxin ( $\mathrm{rat} A$ ) gene is encoded by the $E$. coli genome [119]. This toxic protein inhibits the initiation of translation by associating specifically with the ribosome (50S subunit) and also inhibiting 705 ribosome formation. This gene has no effect on cellular mRNAs and is unable to dissociate 70S ribosomes [58]. Inducing expression of the ratA gene causes inhibition of cell growth $[58,119]$. A recent study has shown a positive association between rat gene and patients with $C D$, and the detection of this toxic gene is likely to play a crucial role in AIEC pathogenesis in patients with CD [30]. This gene was isolated and identified from adherent and invasive strains isolated from the ileum of patients with Crohn's disease [120].

\section{Quantitative real-time PCR-based analysis for adherent-invasive $\boldsymbol{E}$. coli}

AIEC strains are genetically variable, and the virulence factors are nonspecific. Recent studies have linked the AIEC strains with CD [121-124]. At present, time-consuming techniques such as in vitro infection of cell cultures that has been used to determine the ability of AIEC strain to adhere and invade epithelial cells as well as to survive and replicate within macrophage cells are required for the assessment of the pathogenicity of AIEC strains. However, these time-consuming techniques do not enable precise quantification of AIEC strains from human samples. A fast, sensitive, and successful quantitative real-time PCR (qRt-PCR) technique is applied nowadays for identification and quantification of microbes from clinical samples [33, 37, 125, 126].

A qRT-PCR assay for quantification of the LF82 strain and total $E$. coli in human intestinal samples from CD patients has been reported. Targeted bacteria have been quantified, and a standard curve has been made. Proper primers were designed to ensure high specificity detection. This assay showed high specificity and robustness for the detection of LF82 strain in human intestinal tissues. Combining this technique with other techniques such as phenotypic assays (adhesion and replication in cell lines) will help in the isolation and characterisation of LF82 strain [39].

\section{Conclusions}

Considerable evidence indicates that $E$. coli and particularly AIEC strains are involved in the pathogenesis of CD. Although the prevalence of AIEC in the mucosa of CD patients has been reported in many studies, the abundance of AIEC varies significantly between studies. The virulence genes that relate to adhesion, invasion, capsule formation, iron acquisition, and toxin production among $E$. coli isolates from CD patients are thought to be major contributors for colonisation of $E$. coli in the $\mathrm{Gl}$ tract. These virulence factors can define the pathophysiology of CD like intestinal inflammation, bacterial translocation through mucosa, and formation of granuloma. A decade ago, the AIEC pathotype was discovered, and ever since, studies have reported the ability of AIEC to adhere and to invade intestinal epithelial cells, as well as to persist and survive inside macrophage cells. There are also several studies focusing on the detection of AIEC mechanisms in CD pathogenicity, and epidemiological studies have been conducted on this disease, but further research is needed to confirm the role of AIEC on CD. Using time-consuming techniques to identify the AIEC pathotype is an important limitation, and molecular tools are needed. Moreover, molecular-based studies are needed to assist in the identification of the genetic elements among AIEC pathotypes, which can be a major contributor to understanding the pathogenicity of AIECS and their interaction with the host, and also could help in the detection of therapeutic agents for CD. Finally, to reach a definitive conclusion about the role of microbes and specifically the AIEC pathotype in CD development, it is necessary to identify AIEC genes related to disease pathogenesis.

\section{Conflict of interest}

The authors declare no conflict of interest. 


\section{References}

1. Qin J, Li R, Raes J, et al. A human gut microbial gene catalogue established by metagenomic sequencing. Nature 2010; 464: 59-65.

2. Mazmanian SK, Cui HL, Tzianabos AO, Kasper DL. An immunomodulatory molecule of symbiotic bacteria directs maturation of the host immune system. Cell 2005; 122; 107-18.

3. Dreux N, Denizot J, Martinez-Medina M, et al. Point mutations in FimH adhesion of Crohn's disease-associated adherent-invasive Escherichia coli enhance intestinal inflammatory response. PLoS Pathog 2013; 9: e1003141.

4. Kinross JM, von Roon AC, Holmes E, et al. The human gut microbiome: implications for future health care. Curr Gastroenterol Rep 2008; 10: 396-403.

5. Mazmanian SK, Round JL, Kasper DL. A microbial symbiosis factor prevents intestinal inflammatory disease. Nature 2008; 453: 620-5.

6. Penders J, Stobberingh EE, Brandt PA, Thijs C. The role of the intestinal microbiota in the development of atopic disorders. Allergy 2007; 62: 1223-36.

7. Wen L, Ley RE, Volchkov PY, et al. Innate immunity and intestinal microbiota in the development of type 1 diabetes. Nature 2008; 455: 1109-13.

8. Backhed F, Ley RE, Sonnenburg JL, et al. Host-bacterial mutualism in the human intestine. Science 2005; 307: 1915-20.

9. Dumas ME, Barton RH, Toye A, et al. Metabolic profiling reveals a contribution of gutmicrobiota to fatty liver phenotype in insulin-resistant mice. Proc Natl Acad Sci USA 2006; 103 : 12511-6.

10. Podolsky DK. The current future understanding of inflammatory bowel disease. Best Pract Res Clin Gastroenterol 2002; 16: 933-43.

11. Shanahan F. Crohn's disease. Lancet 2002; 359: 62-9.

12. Targan SR, Karp LC. Defects in mucosal immunity leading to ulcerative colitis. Immunol Rev 2005; 206: 296-305.

13. Bouma G, Strober W. The immunological and genetic basis of inflammatory bowel disease. Nat Rev Immunol 2003; 3: 521-33.

14. Xavier RJ, Podolsky DK. Unravelling the pathogenesis of inflammatory bowel disease. Nature 2007; 448: 427-34.

15. Sartor RB. Microbial influences in inflammatory bowel diseases. Gastroenterology 2008; 134: 577-94.

16. Willing B, Halfvarson J, Dicksved J, et al. Twin studies reveal specific imbalances in the mucosa-associated microbiota of patients with ileal Crohn's disease. Inflamm Bowel Dis 2009; 15: 653-60.

17. Andoh A, Imaeda H, Aomatsu T, et al. Comparison of the fecal microbiota profiles between ulcerative colitis and Crohn's disease using terminal restriction fragment length polymorphism analysis. J Gastroenterol 2011; 46: 479-86.

18. Machiels K, Joossens M, Sabino J, et al. A decrease of the butyrate-producing species Roseburia hominis and Faecalibacterium prausnitzii defines dysbiosis in patients with ulcerative colitis. Gut 2014; 63: 1275-83.

19. Martinez-Medina M, Aldeguer X, Gonzalez-Huix F, et al. Abnormal microbiota composition in the ileocolonic mucosa of Crohn's disease patients as revealed by polymerase chain reaction-denaturing gradient gel electrophoresis. Inflamm Bowel Dis 2006; 12: 1136-45.

20. Rhodes JM. The role of Escherichia coli in inflammatory bowel disease. Gut 2007; 56: 610-2.

21. Rolhion N, Darfeuille-Michaud A. Adherent-invasive Escherichia coli in inflammatory bowel disease. Inflamm Bowel Dis 2007; 13: 1277-83.

22. Dogan B, Scherl E, Bosworth B, et al. Multidrug resistance is common in Escherichia coli associated with ileal Crohn's disease. Inflamm Bowel Dis 2013; 19: 141-50.

23. Sha S, Xu B, Wang X, et al. The biodiversity and composition of the dominant fecal microbiota in patients with inflammatory bowel disease. Diagnostic Microbiol Infect Dis 2013; 75 : 245-51.

24. Elliott TR, Hudspith BN, Wu G, et al. Quantification and characterization of mucosa-associated and intracellular Escherichia coli in inflammatory bowel disease. Inflamm Bowel Dis 2013; 19: 2326-38.

25. O'Brien CL, Pavli P, Gordon DM, Allison GE. Detection of bacterial DNA in lymph nodes of Crohn's disease patients using high throughput sequencing. Gut 2014; 63: 1596-606.

26. Lopez-Siles M, Martinez-Medina M, Busquets D, et al. Mucosa-associated Faecalibacterium prausnitzii and Escherichia coli co-abundance can distinguish irritable bowel syndrome and inflammatory bowel disease phenotypes. Int J Med Microbiol 2014; 304: 464-75.

27. Zou Y, He L, Wu CH, et al. PSF is an IbeA-binding protein contributing to meningitic Escherichia coli $K 1$ invasion of human brain microvascular endothelial cells. Med Microbiol Immunol 2007; 196: 135-43.

28. Kabeerdoss J, Jayakanthan P, Pugazhendhi S, Ramakrishna BS. Alterations of mucosal microbiota in the colon of patients with inflammatory bowel disease revealed by real time polymerase chain reaction amplification of $16 \mathrm{~S}$ ribosomal ribonucleic acid. Indian J Med Res 2015; 142: 23-32.

29. O’Brien CL, Bringer MA, Holt KE, et al. Comparative genomics of Crohn's disease-associated adherent-invasive Escherichia coli. Gut 2017; 66: 1382-9.

30. Céspedes S, Saitz W, Del Canto F, et al. Genetic diversity and virulence determinants of Escherichia coli strains isolated from patients with Crohn's disease in Spain and Chile. Front Microbiol 2017; 8: 639.

31. Winter SE, Winter MG, Xavier MN, et al. Host-derived nitrate boosts growth of E. coli in the inflamed gut. Science 2013; 339: 708-11.

32. Willing B, Halfvarson J, Dicksved J, et al. Twin studies reveal specific imbalances in the mucosa-associated microbiota of patients with ileal Crohn's disease. Inflamm Bowel Dis 2009; 15: 653-60.

33. Baumgart M, Dogan B, Rishniw M, et al. Culture independent analysis of ileal mucosa reveals a selective increase in invasive Escherichia coli of novel phylogeny relative to depletion of Clostridiales in Crohn's disease involving the ileum. ISME J 2007; 1: 403-18.

34. Sasaki M, Sitaraman SV, Babbin BA, et al. Invasive Escherichia coli are a feature of Crohn's disease. Lab Invest 2007; 87: 1042-54.

35. Gophna U, Sommerfeld K, Gophna S, et al. Differences between tissue-associated intestinal microfloras of patients 
with Crohn's disease and ulcerative colitis. J Clin Microbiol 2006; 44: 4136-41.

36. Martin HM, Campbell BJ, Hart CA, et al. Enhanced Escherichia coli adherence and invasion in Crohn's disease and colon cancer. Gastroenterology 2004; 127: 80-93.

37. Martinez-Medina M, Aldeguer X, Lopez-Siles M, et al. Molecular diversity of Escherichia coli in the human gut: new ecological evidence supporting the role of adherent-invasive E. coli (AIEC) in Crohn's disease. Inflamm Bowel Dis 2009; 15: 872-82.

38. Neut C, Bulois P, Desreumaux P, et al. Changes in the bacterial flora of the neoterminal ileum after ileocolonic resection for Crohn's disease. Am J Gastroenterol 2002; 97: 939-46.

39. Jensen SR, Nielsen OH, Brix S. Are NOD2 polymorphisms linked to a specific disease endophenotype of Crohn's disease? Inflamm Bowel Dis 2011; 17: 2392-401.

40. Dreux N, Denizot J, Martinez-Medina M, et al. Point mutations in FimH adhesin of Crohn's disease-associated adherent-invasive Escherichia coli enhance intestinal inflammatory response. PLoS Pathog 2013; 9: e1003141.

41. Rolhion N, Barnich N, Bringer MA, et al. Abnormally expressed ER stress response chaperone Gp96 in CD favours adherent-invasive Escherichia coli invasion. Gut 2010; 59: 1355-62.

42. Bringer MA, Barnich N, Glasser AL, et al. HtrA stress protein is involved in intramacrophagic replication of adherent and invasive Escherichia coli strain LF82 isolated from a patient with Crohn's disease. Infect Immun 2005; 73: 712-21.

43. Bringer MA, Rolhion N, Glasser AL, Darfeuille-Michaud A. The oxidoreductase DsbA plays a key role in the ability of the Crohn's disease-associated adherent-invasive Escherichia coli strain LF82 to resist macrophage killing. J Bacteriol 2007; 189: 4860-71.

44. Sokurenko EV, Chesnokova V, Doyle RJ, Hasty DL. Diversity of the Escherichia coli type 1 fimbrial lectin. Differential binding to mannosides and uroepithelial cells. J Biol Chem 1997; 272: 17880-6.

45. Chassaing B, Rolhion N, de Vallée A, et al. Crohn disease: associated Adherent invasive E. coli bacteria target mouse and human Peyer's patches via long polar fimbriae. J Clin Invest 2011; 121: 966-75

46. Barnich N, Carvalho FA, Glasser AL, et al. CEACAM6 acts as a receptor for adherent invasive $\mathrm{E}$. coli, supporting ileal mucosa colonization in Crohn disease. J Clin Invest 2007; 117 1566-74.

47. Barnich N, Darfeuille-Michaud A. Abnormal CEACAM6 expression in Crohn disease patients favors gut colonization and inflammation by adherent-invasive E. coli. Virulence 2010; 1: 281-2.

48. Boudeau J, Barnich N, Darfeuille-Michaud A. Type 1 pili-mediated adherence of Escherichia coli strain LF82 isolated from Crohn's disease is involved in bacterial invasion of intestinal epithelial cells: type 1 pili and E. coli invasion. Mol Microbiol 2004; 39: 1272-84.

49. Cieza RJ, Hu J, Ross BN, et al. The IbeA invasin of adherent-invasive Escherichia coli mediates interaction with intestinal epithelia and macrophages. Infect Immun 2015; 83: 1904-18.

50. Prorok-Hamon M, Friswell MK, Alswied A, et al. Colonic mu cosa-associated diffusely adherent afaC+ Escherichia coli ex- pressing IpfA and pks are increased in inflammatory bowel disease and colon cancer. Gut 2014; 63: 761-70.

51. Rolhion N, Carvalho FA, Darfeuille-Michaud A. OmpC and the sigma (E) regulatory pathway are involved in adhesion and invasion of the Crohn's disease-associated Escherichia coli strain LF82. Mol Microbiol 2007; 63: 1684-700.

52. Sarabi Asiabar A, Asadzadeh Aghdaei H, Sabokbar A, et al. Investigation of adherent-invasive $\mathrm{E}$. coli in patients with Crohn's disease. Med J Islam Repub Iran 2018; 32: 11.

53. Dogan B, Suzuki H, Herlekar D, et al. Inflammation-associated adherent-invasive Escherichia coli are enriched in pathways for use of propanediol and iron andM-cell translocation. Inflamm Bowel Dis 2014; 20: 1919-32.

54. Conte MP, Aleandri M, Marazzato M, et al. The adherent/invasive Escherichia coli strain LF82 invades and persists in human prostate cell Line RWPE-1, activating a strong inflammatory response. Infect Immun 2016; 84: 3105-13.

55. Zhang Y, Rowehl L, Krumsiek JM, et al. Identification of candidate adherent invasive E. coli signature transcripts by genomic/transcriptomic analysis. PLoS One 2015; 10: e0130902.

56. Claret L, Miquel S, Vieille N, et al. The flagellar sigma factor FliA regulates adhesion and invasion of Crohn disease-associated Escherichia coli via a cyclic dimeric GMP dependent pathway. J Biol Chem 2007; 282: 33275-83.

57. Barnich N, Boudeau J, Claret L, et al. Regulatory and functional co-operation of flagella and type 1 pili in adhesive and invasive abilities of AIEC strain LF82 isolated from a patient with Crohn's disease. Mol Microbiol 2003; 48: 781-94.

58. Zhang Y, Inouye M. RatA (YfjG), an Escherichia coli toxin, inhibits 705 ribosome association to block translation initiation. Mol Microbiol 2011; 79: 1418-29.

59. Simonsen KT, Nielsen G, Bjerrum JV, et al. A role for the RNA chaperone $\mathrm{Hfq}$ in controlling adherent-invasive Escherichia coli colonization and virulence. PLoS One 2011; 6: e16387.

60. Bringer MA, Barnich N, Glasser AL, et al. HtrA stress protein is involved in intra-macrophagic replication of adherent and invasive Escherichia coli strain LF82 isolated from a patient with Crohn's disease. Infect Immun 2005; 73: 712-21.

61. Bringer MA, Rolhion N, Glasser AL, et al. The oxidoreductase DsbA plays a key role in the ability of the Crohn's disease-associated adherent-invasive Escherichia coli strain LF82 to resist macrophage killing. J Bacteriol 2007; 189: 4860-71.

62. Sarabi Asiabar A, Asadzade Aghdaei H, Sabokbar A, et al. Prevalence of adherent-invasive Escherichia coli with fim $\mathrm{H}$ gene isolated from Iranian patients with ulcerative colitis. Jundishapur J Microbiol 2017; 10: e13858.

63. lebba V, Conte MP, Lepanto MS, et al. Microevolution in fimH gene of mucosa-associated Escherichia coli strains isolated from pediatric patients with inflammatory bowel disease. Infect Immun 2012; 80: 1408-17.

64. Huang SH, Stins MF, Kim KS. Bacterial penetration across the blood brain barrier during the development of neonatal meningitis. Microbes Infect 2000; 2: 1237-44

65. Huang SH, Wan ZS, Chen YH, et al. Further characterization of Escherichia coli brain microvascular endothelial cell invasion gene ibeA by deletion, complementation, and protein expression. J Infect Dis 2001: 183: 1071-8. 
66. Homeier T, Semmler T, Wieler LH, Ewers C. The gimA locus of extra-intestinal pathogenic Escherichia coli: does reductive evolution correlate with habitat and pathotype? PLoS One 2010; 5: e10877.

67. Conte et al. Adherent-invasive Escherichia coli (AIEC) in pediatric Crohn's disease patients: phenotypic and genetic pathogenic features. BMC Res Notes 2014; 7: 748.

68. Cieza RJ, Hu J, Ross BN, et al. The IbeA invasin of adherent-invasive Escherichia coli mediates interaction with intestinal epithelia and macrophages. Infect Immun 2015; 83: 1904-18.

69. Zou Y, He L, Huang SH. Identification of a surface protein on human brain microvascular endothelial cells as vimentin interacting with Escherichia coli invasion protein IbeA. Biochem Biophys Res Commun 2006; 351: 625-30.

70. Chi F, Wang Y, Gallaher TK, et al. Identification of IbeR as a stationary-phase regulator in meningitic Escherichia coli $\mathrm{K} 1$ that carries a loss-of-function mutation in rpoS. J Biomed Biotechnol 2009; 2009: 520283.

71. Zou Y, He L, Chi F, et al. Involvement of Escherichia coli K1 ibeT in bacterial adhesion that is associated with the entry into human brain microvascular endothelial cells. Med Microbiol Immunol 2008; 197: 337-44

72. Jann K, Jann B. Capsules of Escherichia coli, expression and biological significance. Can J Microbiol 1992; 38: 705-10.

73. Johnson JR. Virulence factors in Escherichia coli urinary tract infection. Clin Microbiol Rev 1991; 4: 80-128.

74. Burns SM, Hull SI. Loss of resistance to ingestion and phagocytic killing by O- and K-mutants of a uropathogenic Escherichia coli 075:K5 strain. Infect Immun 1999; 67: 3757-62.

75. Hoffman JA, Wass C, Stins MF, Kim KS. The capsule supports survival but not traversal of Escherichia coli K1 across the blood-brain barrier. Infect Immun 1999; 67: 3566-70.

76. Jann K, Jann B. The K antigens of Escherichia coli. Prog Allergy 1983; 33: 53-79.

77. Kim KS, Itabashi H, Gemski P, et al. The K1 capsule is the critical determinant in the development of Escherichia coli meningitis in the rat. J Clin Investig 1992; 90: 897-905.

78. Russo TA, Liang Y, Cross AS. The presence of K54 capsular polysaccharide increases the pathogenicity of Escherichia coli in vivo. J Infect Dis 1994; 169: 112-8.

79. Drake CR, Boulnois GJ, Roberts IS. The Escherichia coli serA-linked capsule locus and its flanking sequences are polymorphic, genetic evidence for the existence of more than two groups of capsule gene clusters. J Gen Microbiol 1993; 139: 1707-14.

80. Pearce R, Roberts IS. Cloning and analysis of gene clusters for production of the Escherichia coli $\mathrm{K} 10$ and $\mathrm{K} 54$ antigens: identification of a new group of serA-linked capsule gene clusters. J Bacteriol 1995; 177: 3992-7.

81. Roberts I, Mountford R, High N, et al. Molecular cloning and analysis of genes for production of K5, K7, K12, and $\mathrm{K} 92$ capsular polysaccharides in Escherichia coli. J Bacteriol 1986; 168: 1228-33.

82. Roberts IA, Mountford R, Hodge R, et al. Common organization of gene clusters for production of different capsular polysaccharides ( $\mathrm{K}$ antigens) in Escherichia coli. J Bacteriol 1988; 170: 1305-10.
83. Roberts M, Roberts I, Korhonen TK, et al. DNA probes for K-antigen (capsule) typing of Escherichia coli. J Clin Microbiol 1988; 26: 385-7.

84. Russo TA, Wenderoth S, Carlino UB, et al. Identification, genomic organization, and analysis of the group III capsular polysaccharide genes kpsD, kpsM, kpsT, and kpsE from an extra-intestinal isolate of Escherichia coli (CP9, O4/K54/H5). J Bacteriol 1998; 180: 338-49.

85. Burns SM, Hull SI. Loss of resistance to ingestion and phagocytic killing by $\mathrm{O}(-)$ and $\mathrm{K}(-)$ mutants of a uropathogenic Escherichia coli 075:K5 strain. Infect Immun 1999; 67: 3757-62.

86. Burns SM, Hull SI. Comparison of loss of serum resistance by defined lipopolysaccharide mutants and an acapsular mutant of uropathogenic Escherichia coli 075 K5. Infect Immun 1998; 66: 4244-53.

87. Anderson GG, Goller CC, Justice S, et al. Polysaccharide capsule and sialic acid-mediated regulation promote biofilm-like intracellular bacterial communities during cystitis. Infect Immun 2010; 78: 963-75.

88. Troy FA II. Polysialylation: from bacteria to brains. Glycobiology 1992; 2: 5-23.

89. Dale AP, Woodford N. Extra-intestinal pathogenic Escherichia coli (ExPEC): disease, carriage and clones. J Infect 2015; 71 : 615-26.

90. Boudeau J, Glasser AL, Masseret E, et al. Invasive ability of an Escherichia coli strain isolated from the ileal mucosa of a patient with Crohn's disease. Infect Immun 1999; 67: 4499-509.

91. Glasser AL, Boudeau J, Barnich N, et al. Adherent invasive Escherichia coli strains from patients with Crohn's disease survive and replicate within macrophages without inducing host cell death. Infect Immun 2001; 69: 5529-37.

92. Darfeuille-Michaud A, Boudeau J, Bulois P, et al. High prevalence of adherent-invasive Escherichia coli associated with ileal mucosa in Crohn's disease. Gastroenterology 2004; 127: 412-21.

93. Carniel E, Guiyoule A, Guilvout I, Mercereau-Puijalon O. Molecular cloning, iron-regulation and mutagenesis of the irp2 gene encoding HMWP2, a protein specific for highly pathogenic Yersinia. Mol Microbiol 1992; 6: 379-88.

94. Guerinot ML. Microbial iron transport. Annu Rev Microbiol 1994; 48: 743-72.

95. Van Heyningen WE, Gladstone GP. The neurotoxin of Shigella shigae3. The effect of iron on production of the foxin. $\mathrm{Br}$ J Exptt Pathot 1953; 34: 221-9.

96. Pappenheimer Jr AM. Diphtheria toxin. Ann Rev Biochem 1977; A6: 69-94.

97. O'Brien AD, Newland JW, Miller SF, et al. Shiga-iike toxin-converting phages from Escherichia coli strains that cause haemorrhagic colitis or infantile diarrhoea. Science 1984; 226: 694-6.

98. Welch RA, Patchen Dellinger E, Minshew B, Falkow S. Haemotysin contributes to virulence of extra-intestinal E. coli infections. Nature 1981; 294: 665-7.

99. Poole K, Braun V. Iron regulation of Serratia marcescens hemolysin gene expression. Infect Immun 1988; 56: 2967-71.

100. Stoebner JA, Payne SM. Iron-regulated hemolysin production and utilization of heme and hemoglobin by Vibrio choterae. Infect Immun 1988; 56: 2891-5. 
101. Koster W, Braun V. Iron-hydroxamate transport into Escherichia coli K12: localization of FhuD in the periplasm and of FhuB in the cytoplasmic membrane. Mol Gen Genet 1989; 217: 233-9.

102. Torres AG, Payne SM. Haem iron-transport system in entero-haemorrhagic Escherichia coli O157:H7. Mol Microbiol 1997; 23: 825-33.

103. Wyckoff EE, Duncan D, Torres AG, et al. Structure of the Shigella dysenteriae haem transport locus and its phylogenetic distribution in enteric bacteria. Mol Microbiol 1998; 28: 1139-52.

104. Hampe J, Franke A, Rosenstiel P, et al. A genome-wide association scan of nonsynonymous SNPs identifies a susceptibility variant for Crohn disease in ATG16L1. Nat Genet 2007; 39. 207-11.

105. Barnich N, Carvalho FA, Glasser AL, et al. CEACAM6 acts as a receptor for adherent-invasive E. coli, supporting ileal mucosa colonization in Crohn disease. J Clin Invest 2007; 117 : 1566-74.

106. Bringer MA, Billard E, Glasser AL, et al. Replication of Crohn's disease associated AIEC within macrophages is dependent on TNF-alpha secretion. Lab Invest 2012; 92: 411-9.

107. Leibold EA, Guo B. Iron-dependent regulation of ferritin and transferrin receptor expression by the iron-responsive element binding protein. Annu Rev Nutr 1992; 12: 345-68.

108. Klausner RD, Rouault TA, Harford JB. Regulating the fate of mRNA: the control of cellular iron metabolism. Cell 1993; 72 19-28.

109. Theil EC. The IRE (iron regulatory element) family: structures which regulate $m$ RNA translation or stability. Biofactors 1993; 4: 87-93.

110. Cairo G, Recalcati S. Iron-regulatory proteins: molecular biology and pathophysiological implications. Exp Rev Mol Med 2007; 9: 1-13.

111. Heesemann J, Hantke K, Vocke T, et al. Virulence of Yersinia enterocolitica is closely associated with siderophore production, expression of an iron-repressible outer membrane polypeptide of $65000 \mathrm{Da}$ and pesticin sensitivity. Mol Microbiol 1993; 8: 397-408.

112. Rakin A, Saken E, Harmsen D, Heesemann J. The pesticin receptor of Yersinia enterocolitica: a novel virulence factor with dual function. Mol Microbiol 1994; 13: 253-63.

113. Schubert S, Picard B, Gouriou S, et al. Yersinia high-pathogenicity island contributes to virulence in Escherichia coli causing extra-intestinal infections. Infect Immun 2002; 70 5335-7.

114. Schubert S, Fischer D, Heesemann J. Ferric enterochelin transport in Yersinia enterocolitica: molecular and evolutionary aspects. J Bacteriol 1999; 181: 6387-95.

115. Hancock V, Dahl M, Klemm P. Abolition of biofilm formation in urinary tract Escherichia coli and Klebsiella isolates by metal interference through competition for fur. Appl Environ Microbiol 2010; 76: 3836-41.

116. Bach S, De Almeida A, Carniel E. The Yersinia high pathogenicity island is present in different members of the family Enterobacteriaceae. FEMS Microbiol Lett 2000; 183: 289-94.

117. Karch H, Schubert S, Zhang D, et al. A genomic island, termed high pathogenicity island, is present in certain non-0157 shiga toxin producing Escherichia coli clonal lineages. Infect Immun 1999; 67: 5994-6001.

118. Xu JG, Cheng B, Wen X, et al. High pathogenicity island of Yersinia spp. in Escherichia coli strains isolated from diarrhea patients in China. J Clin Microbiol 2000; 38: 4672-5.

119. Brown JM, Shaw KJ. A novel family of Escherichia coli toxin-antitoxin gene pairs. J Bacteriol 2003; 185: 6600-8.

120. Baumgart M, Dogan B, Rishniw M, et al. Culture independent analysis of ileal mucosa reveals a selective increase in invasive Escherichia coli of novel phylogeny relative to depletion of Clostridiales in Crohn's disease involving the ileum. ISME J 2007; 1: 403-18.

121. Darfeuille-Michaud A, Neut C, Barnich N, et al. Presence of adherent Escherichia coli strains in ileal mucosa of patients with Crohn's disease. Gastroenterology 1998; 115: 1405-13.

122. Schultsz C, Van Den Berg FM, Ten Kate FW, et al. The intestinal mucus layer from patients with inflammatory bowel disease harbors high numbers of bacteria compared with controls. Gastroenterology 1999; 117: 1089-97.

123. Ryan P, Kelly RG, Lee G, et al. Bacterial DNA within granulomas of patients with Crohn's disease- detection by laser capture microdissection and PCR. Am J Gastroenterol 2004; 99: 1539-43.

124. De la Fuente M, Franchi L, Araya D, et al. Escherichia coli isolates from inflammatory bowel diseases patients survive in macrophages and activate NLRP3 inflammasome. Int J Med Microbiol 2014; 304: 384-92.

125. Furet JP, Firmesse O, Gourmelon M, et al. Comparative assessment of human and farm animal faecal microbiota using real-time quantitative PCR. FEMS Microbiol Ecol 2009; 68: 351-62.

126. Huijsdens XW, Linskens RK, Mak M, et al. Quantification of bacteria adherent to gastrointestinal mucosa by real-time PCR. J Clin Microbiol 2002; 40: 4423-7.

Received: 18.09 .2019

Accepted: 4.11 .2019 